\title{
2-Fluorophenol degradation by aerobic granular sludge in a sequencing batch reactor
}

\author{
Anouk F. Duque ${ }^{a}$, Vânia S. Bessa ${ }^{a}$, Maria F. Carvalho ${ }^{a}$, Merle K. de Kreuk $^{b, c}$, \\ Mark C.M. van Loosdrecht ${ }^{b}$, Paula M.L. Castro ${ }^{a, *}$ \\ ${ }^{a} \mathrm{CBQF} /$ Escola Superior de Biotecnologia, Universidade Católica Portuguesa, Rua Dr. António Bernardino de Almeida, \\ 4200-072 Porto, Portugal \\ ${ }^{\mathrm{b}}$ Department of Biotechnology, Delft University of Technology, Julianalaan 67, 2628BC Delft, The Netherlands \\ ${ }^{\mathrm{c}}$ Waterboard Hollandse Delta, Handelsweg 100, 2988DC Ridderkerk, The Netherlands
}

\section{A R T I C L E I N F O}

Article history:

Received 6 June 2011

Received in revised form

22 September 2011

Accepted 15 October 2011

Available online 25 October 2011

Keywords:

Aerobic granular sludge (GS)

2-Fluorophenol (2-FP)

Bioaugmentation

Sequencing batch reactor (SBR)

Wastewater treatment

\begin{abstract}
A B S T R A C T
Aerobic granular sludge is extremely promising for the treatment of effluents containing toxic compounds, and it can economically compete with conventional activated sludge systems. A laboratory scale granular sequencing batch reactor (SBR) was established and operated during 444 days for the treatment of an aqueous stream containing a toxic compound, 2-fluorophenol (2-FP), in successive phases. Initially during ca. 3 months, the SBR was intermittently fed with $0.22 \mathrm{mM}$ of 2-FP added to an acetate containing medium. No biodegradation of the target compound was observed. Bioaugmentation with a specialized bacterial strain able to degrade 2-FP was subsequently performed. The reactor was thereafter continuously fed with 0.22 and $0.44 \mathrm{mM}$ of 2-FP and with $5.9 \mathrm{mM}$ of acetate (used as co-substrate), for 15 months. Full degradation of the compound was reached with a stoichiometric fluoride release. The 2-FP degrading strain was successfully retained by aerobic granules, as shown through the recovering of the strain from the granular sludge at the end of the experiment. Overall, the granular SBR has shown to be robust, exhibiting a high performance after bioaugmentation with the 2-FP degrading strain. This study corroborates the fact that bioaugmentation is often needed in cases where biodegradation of highly recalcitrant compounds is targeted.
\end{abstract}

(c) 2011 Elsevier Ltd. All rights reserved.

\section{Introduction}

The use of organofluorine compounds as aerosol propellants, surfactants, agrochemicals, adhesives, refrigerants, fire retardants, pharmaceuticals, among others, has increased during the last century (Key et al., 1997). They may have significant biological effects as enzyme inhibitors, modifiers of cell-cell communication, disrupting membrane transport and processes for energy generation. Biodegradation of fluoroaromatic compounds, among them fluorophenols, has been scarcely investigated. They are usually biodegraded via (halo)catechols (Haggblom, 1992; Murphy et al., 2009). The conversion of these compounds is often the rate limiting step and therefore they easily accumulate in reactors (Carvalho et al., 2006a; Fava et al., 1995). Micropollutants need to be removed efficiently from wastewater to protect receiving waterbodies from their ecotoxicological effects. The removal of (halo)aromatics from wastewaters using biological technologies has been shown before (Buitron et al., 2005;

\footnotetext{
* Corresponding author. Tel.: +35122 5580059; fax: +351225090351.

E-mail addresses: afduque@mail.esb.ucp.pt (A.F. Duque), vsbessa@esb.ucp.pt (V.S. Bessa), mfcarvalho@esb.ucp.pt (M.F. Carvalho), m.dekreuk@wshd.nl (M.K. de Kreuk), m.c.m.vanloosdrecht@tnw.tudelft.nl (M.C.M. van Loosdrecht), plc@esb.ucp.pt, plcastro@esb.ucp.pt (P.M.L. Castro)

0043-1354/\$ - see front matter @ 2011 Elsevier Ltd. All rights reserved.

doi:10.1016/j.watres.2011.10.033
} 
Carvalho et al., 2006b; Osuna et al., 2008). As these pollutants occur in wastewaters discontinuously and at low concentrations, maintenance of a good population of (halo)aromatics degraders in bioreactors is highly desirable.

Bioreactor systems with high biomass retention are extremely promising for the treatment of wastewaters containing toxic compounds. The granular sludge SBR is such a reactor type. The granular sludge SBR is a relative novel design, which has especially gained interest after the recent observation that under aerobic conditions biomass can be grown in granules similar to anaerobic granular sludge reactors (Beun et al., 1999, 2000, 2002; Morgenroth et al., 1997). Aerobic granular sludge presents several advantages over activated sludge, such as excellent settling properties, high biomass retention and biosorption, ability to deal with high organic loading rates and to perform simultaneously diverse biological processes, such as COD, N and P removal (De Bruin et al., 2004; De Kreuk et al., 2005; Xu et al., 2004). Aerobic granular sludge can economically compete with the conventional activated sludge systems. Recently, Carucci et al. (2010) compared a granular sludge sequencing batch reactor (GSBR) with a conventional sequencing batch reactor and a membrane bioreactor for the treatment of 4-chlorophenol. They reported the GSBR as the most suitable technology when the critical parameters are low land requirement, system simplicity/flexibility and short start up times. Furthermore, it has been reported in literature that aerobic granular sludge can successfully degrade and deal with the presence of phenol and chlorinated compounds, suggesting that the granular structure protects the microorganisms against toxicity (Carucci et al., 2008, 2009, 2010; Jiang et al., 2002; Tay et al., 2005a, b; Wang et al., 2007). Nevertheless, if unacclimated sludge is not able to readily degrade a toxic or a poorly degradable compound, bioaugmentation with specialized strains can be an option, a strategy that is lately gaining more interest (Quan et al., 2003; Rittmann and Whiteman, 1994; Yu and Mohn, 2001). There are two main problems associated with the augmentation of a bioreactor: (i) as toxic and/or recalcitrant (micro)pollutants may appear intermittently and/ or may be present at very low concentrations, loss of degrading capacity by the specialized strain may occur, due to the absence of the selective pressure (ii) the presence of protozoa can affect the success of the bioaugmentation, as the added culture can be grazed by these microorganisms. Nevertheless, Quan et al. (2003) has shown the success of bioaugmenting a flocculated sludge SBR with an immobilized mixed culture able to biodegrade 2,4-dichlorophenol.

The main aim of this study was to investigate the robustness and performance of a laboratory scale SBR with aerobic granular sludge toward shock loadings of 2-FP, using acetate as the growth substrate, before and after bioaugmentation with a specialized strain able to degrade this compound.

\section{Material and methods}

\subsection{SBR set up and operation}

A $2.5 \mathrm{~L} \mathrm{SBR}$ with $110 \mathrm{~cm}$ height and an internal diameter of $6.5 \mathrm{~cm}$ was established. The experimental set up is schematically shown in Fig. 1. The system was operated in cycles using an automatic timer (Siemens Logo! 230RC) to start and stop pumps for influent, aeration $\left(4 \mathrm{~L} \mathrm{~min}^{-1}\right.$; superficial air velocity of $84.8 \mathrm{~m} \mathrm{~h}^{-1}$ ) and effluent withdrawal. The operating conditions tested in the SBR are described in Table 1. Dissolved oxygen (DO) and $\mathrm{pH}$ were measured online. DO was measured as percentage of the oxygen saturation concentration. The oxygen saturation level was monitored, but not controlled during the cycle. The $\mathrm{pH}$ was maintained at $7.0 \pm 0.8$ by dosing $1 \mathrm{M} \mathrm{NaOH}$ or $1 \mathrm{M} \mathrm{HCl}$.

The reactor was operated in successive cycles of $3 \mathrm{~h}$ (during phases I and II), consisting of 60 min influent feeding (which was introduced in the bottom of the reactor), $112 \mathrm{~min}$ aeration, $3 \mathrm{~min}$ settling and $5 \mathrm{~min}$ effluent withdrawal. During phases III and IV, the aeration period was increased to $652 \mathrm{~min}$ in the $12 \mathrm{~h}$ cycle and then decreased to $412 \mathrm{~min}$ in the $8 \mathrm{~h}$ cycle (phase V) and, afterward, to $172 \mathrm{~min}$ in the $4 \mathrm{~h}$ cycle (phases VI and VII), so that the cycle length would not represent a limitation for all bioconversion processes (Table 1). In each cycle, about $40 \%$ of the reactor liquid was withdrawn. The settling time was chosen such that only particles with a settling velocity larger than $6 \mathrm{~m} \mathrm{~h}^{-1}$ were effectively retained in the reactor. The reactor was operated at a sludge retention time (SRT) of 30 days.

Aerobic granular sludge (500 ml wet granules) was collected from a pilot plant treating sewage, in the Netherlands. This biological phosphate removing sludge was used as inoculum for the start up of the reactor.

\subsubsection{Bioaugmentation with Rhodococcus sp. strain FP1}

For bioaugmentation of the SBR, a bacterial strain able to degrade 2-FP, named as Rhodococcus sp. strain FP1, previously isolated in our laboratories, was used (HM210775) (unpublished). FP1 pure cultures were grown in sealed flasks containing a mineral salts liquid medium (Caldeira et al., 1999) and 2-FP at a concentration of $50 \mathrm{mg} \mathrm{L}^{-1}$. The cultures were incubated on an orbital shaker (100 rpm) at $25^{\circ} \mathrm{C}$. The optical density at $600 \mathrm{~nm}\left(\mathrm{OD}_{600}\right)$ was followed to monitor growth. The reactor was inoculated with $1.25 \mathrm{~L}$ of an FP1 pure culture with an $\mathrm{OD}_{600}$ of 0.8 .

\subsection{Media}

The composition of the SBR influent media was as described by De Kreuk et al. (2005). During shock loadings, $2.38 \mathrm{mM}$ (phases II, III and VII) and $4.76 \mathrm{mM}$ (phases IV-VI) of 2-FP was added to the influent medium. From each media, $89 \mathrm{ml}$ per cycle were dosed together with $772 \mathrm{ml}$ of tap water.

\subsection{Analysis}

The DO concentration in the reactor was measured with a DOsensor (InPro 6820, Mettler-Toledo) and the $\mathrm{pH}$ was monitored using a pH-electrode (InPro 3030, Mettler-Toledo).

Chemical oxygen demand (COD) was determined according to Standard Method 5220 (APHA, 1998).

The concentration of fluoride ions in supernatants was measured with an ion-selective combination electrode (model $\mathrm{CH}-8902$, Mettler-Toledo GmbH, Urdorf, Switzerland), which was calibrated with $\mathrm{NaF}(0.01-5 \mathrm{mM})$ in mineral salts medium 


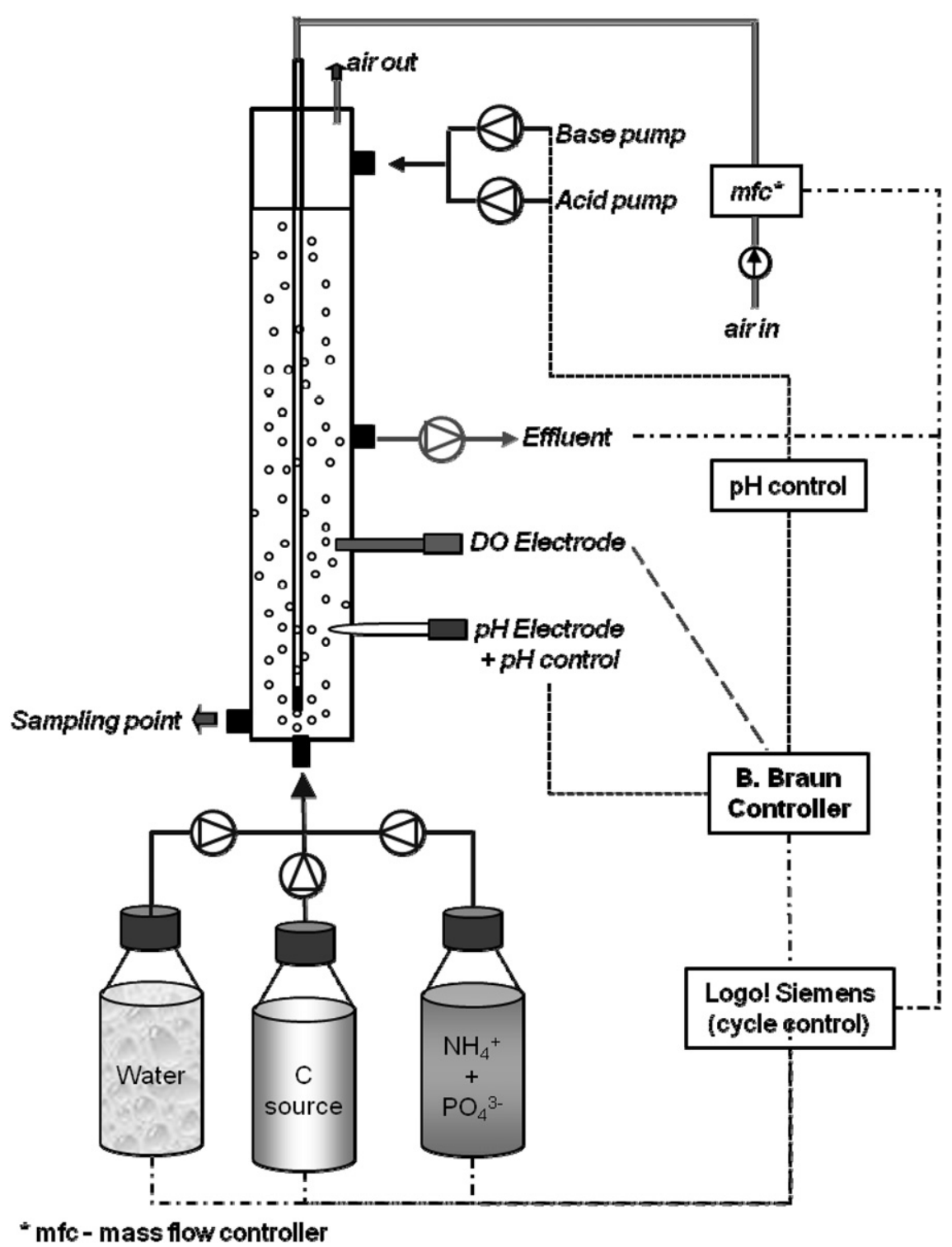

Fig. 1 - Schematic representation of the SBR.

(SBR influent medium without the carbon sources). Biomass was previously removed from culture samples by centrifugation at $7000 \mathrm{rpm}$ for $10 \mathrm{~min}$. The ionic strength of the standards and of the samples was adjusted with a buffer solution, named total ionic strength adjustment solution (TISAB). The composition of the TISAB solution was $\mathrm{NaCl} 1 \mathrm{M}, \mathrm{CH}_{3} \mathrm{COOH}$ $0.25 \mathrm{M}, \mathrm{NaCH}_{3} \mathrm{COO} 0.75 \mathrm{M}$ and sodium citrate $0.002 \mathrm{M}$.

2-FP was analyzed by high performance liquid chromatography (HPLC), on a System Gold 126 (Beckman Coulter, Fullerton, USA) with a LiChroCART 25-4 LiChrospher 100 RP18 reversed-phase column, $5 \mu \mathrm{m}$ particle size (Merck, Darmstadt, Germany). The samples were filtered through a $0.45 \mu \mathrm{m}$ filter prior to HPLC analysis. The mobile phase consisted of $50 \%(\mathrm{v} / \mathrm{v})$ acetonitrile and water and was used with a flow rate of $0.8 \mathrm{ml} \mathrm{min}{ }^{-1}$. The run time was $10 \mathrm{~min}$ (elution time about $5.1 \mathrm{~min}$ ) and the volume injected was $20 \mu \mathrm{l}$. The compound was detected at $220 \mathrm{~nm}$ using a diode array detector.

\subsection{Analysis of the presence of Rhodococcus sp. strain} FP1 in the SBR

\subsubsection{Bacterial isolation and DNA extraction}

In order to obtain a representative sample of the population present in the SBR, a sample of aerobic granular sludge was taken from the reactor during the aeration phase. The granules were then crushed using a sterile potter and pestle. Serial dilutions in saline solution $(0.85 \% \mathrm{w} / \mathrm{v} \mathrm{NaCl})$ were made and $0.1 \mathrm{ml}$ of each dilution was spread onto nutrient agar (NA) (LABM, UK). Plates were incubated at $25^{\circ} \mathrm{C}$ for 3 days. Based on size, morphology and pigmentation, different bacterial colonies were isolated from NA plates using the streak-plate procedure. Genomic DNA from each isolate was extracted by picking a colony with a sterile loop, suspending the cells in $200 \mu \mathrm{L}$ sterile ultrapure water and incubating the suspension for $15 \mathrm{~min}$ at $95^{\circ} \mathrm{C}$. Samples were then kept in ice for $7 \mathrm{~min}$ and vortexed. Subsequently, samples were centrifuged at 
Table 1 - Operating conditions tested in the SBR.

\begin{tabular}{|c|c|c|c|c|c|c|c|c|}
\hline \multirow[t]{2}{*}{ Phase } & \multirow[t]{2}{*}{$\begin{array}{c}\text { Length of } \\
\text { operation (days) }\end{array}$} & \multirow[t]{2}{*}{$\begin{array}{c}\text { Days } \\
\text { of operation }\end{array}$} & \multirow[t]{2}{*}{$\begin{array}{l}\text { Cycle } \\
\text { time (h) }\end{array}$} & \multicolumn{2}{|c|}{$\begin{array}{l}\text { Inlet carbon sources } \\
\text { concentrations (mM) }\end{array}$} & \multirow[t]{2}{*}{$\mathrm{HRT}^{\mathrm{a}}(\mathrm{h})$} & \multicolumn{2}{|c|}{$\mathrm{OLR}^{\mathrm{b}}\left(\mathrm{kg} \mathrm{m}^{-3} \mathrm{~d}^{-1}\right)$} \\
\hline & & & & Acetate & 2-FP & & Acetate & 2-FP \\
\hline I & 0-99 & 99 & 3 & 5.9 & 0 & 7.9 & 1.06 & - \\
\hline $\mathrm{II}^{\mathrm{c}}$ & $100-209$ & 109 & 3 & 5.9 & 0.22 & 7.9 & 1.06 & 0.075 \\
\hline \multicolumn{9}{|c|}{ Bioaugmentation with Rhodococcus sp. strain FP1 } \\
\hline III & $210-222$ & 12 & 12 & 5.9 & 0.22 & 31.6 & 0.26 & 0.019 \\
\hline IV & $223-229$ & 6 & 12 & 5.9 & 0.44 & 31.6 & 0.26 & 0.037 \\
\hline V & $230-266$ & 36 & 8 & 5.9 & 0.44 & 21.1 & 0.40 & 0.056 \\
\hline VI & $267-400$ & 133 & 4 & 5.9 & 0.44 & 10.5 & 0.79 & 0.112 \\
\hline VII & $401-444$ & 43 & 4 & 5.9 & 0.22 & 10.5 & 0.79 & 0.056 \\
\hline
\end{tabular}

$14,000 \mathrm{rpm}$ for $5 \mathrm{~min}$ and the supernatant was transferred to a new sterile microtube. DNA was stored at $-20^{\circ} \mathrm{C}$.

\subsubsection{DNA sequencing analysis}

Isolates were subsequently identified by $16 \mathrm{~S}$ rRNA sequencing analysis. The amplification was carried out with the universal primers f27 and r1492 (Lane, 1991) under standard polymerase chain reaction (PCR) conditions (Rainey et al., 1996), with Taq polymerase from Promega (Madison, WI). The amplified fragments were sequenced by Macrogen Inc. (Seoul, Republic of Korea). To determine the phylogenetic affiliation, similarity analysis was performed using the BLAST program (Altschul et al., 1997).

\subsection{Fluoride adsorption tests performed on granular sludge}

In order to estimate the amount of fluoride adsorbed to the aerobic granules, $20 \mathrm{ml}$ of aerobic granular sludge was taken from the bioreactor at the end of a cycle fed with 2-FP and was added to $500 \mathrm{ml}$ flasks containing $180 \mathrm{ml}$ of SBR medium without 2-FP. The flasks were incubated in an orbital shaker at $25{ }^{\circ} \mathrm{C}, 150 \mathrm{rpm}$. Samples for fluoride analysis were taken periodically during 1 month.

\section{Results and discussion}

\subsection{SBR performance}

A SBR was operated in order to assess its performance when treating a synthetic wastewater containing 2-FP. Several operating scenarios, divided in 7 different phases, were tested (Table 1).

\subsubsection{Before bioaugmentation}

The reactor was inoculated with aerobic granular sludge obtained from a pilot SBR operating in the Netherlands and was operated without oxygen control, which led to dissolved oxygen concentrations during the aeration phase close to saturation. At the SBR start-up the granules were smooth, with a regular shape and dark (Fig. 2a). After 2-3 months of operation (phase I) the granules became denser and with irregular shape (Fig. $2 b$ and c) and after 6 months (phase II) they were larger and with "cauliflower" shape (Fig. 2d). At the end of the experiment (after 1.5 year, phase VII), the granules became very dense and small, looking like sand (Fig. 2e). Tay et al. (2005b) reported that the compact structure of the granules protects them against toxic compounds, minimizing sludge wash out, which could well explain the evolution observed here for the granule morphology.

The overall performance of the SBR after 2-FP feeding is shown in Fig. 3. During phase I (99 days), acetate was fed as the sole carbon and energy source with the objective of achieving stable granules. In phase II, the SBR was exposed to intermittent organic feeding with $0.22 \mathrm{mM}$ of 2-FP (1 cycle/2 days) with an HRT of $7.9 \mathrm{~h}$, in order to evaluate the capacity of the endogenous granule population to biodegrade 2-FP. By operating the SBR at a volume exchange ratio of $40 \%$, the 2-FP concentration inside the bioreactor was diluted to a concentration of $0.09 \mathrm{mM}$. These intermittent 2-FP organic shocks were applied along a period of 109 days. As it can be observed from Fig. 3, 2-FP was not degraded during phase II, with no fluoride release observed and with 2-FP being detected at the outlet, indicating that there was no acclimatization of the biomass to the toxic compound. It has been described in the literature that acetate-fed aerobic granules can easily degrade other recalcitrant compounds (Tay et al., 2005a). This was clearly not observed in this work for 2-FP. Nancharaiah et al. (2008) studied the bioaugmentation of aerobic microbial granules with Pseudomonas putida carrying the TOL plasmid and observed that granules grown in acetate may need long adaptation periods before they can metabolize recalcitrant compounds. Furthermore, they suggested that bioaugmentation could be a rapid and efficient way to provide aerobic granules with the adequate catabolic genes, thus reducing the start-up time. Consequently, in the present study, the SBR was bioaugmented with a bacterial strain able to degrade 2-FP, indicated as Rhodococcus sp. strain FP1, previously isolated in our laboratories (unpublished). As it is known from the literature that the start-up time decreases with the increase in inoculum size (Quan et al., 2003), a 50\% augmentation with a pure culture of Rhodococcus sp. strain FP1 cells was performed. 

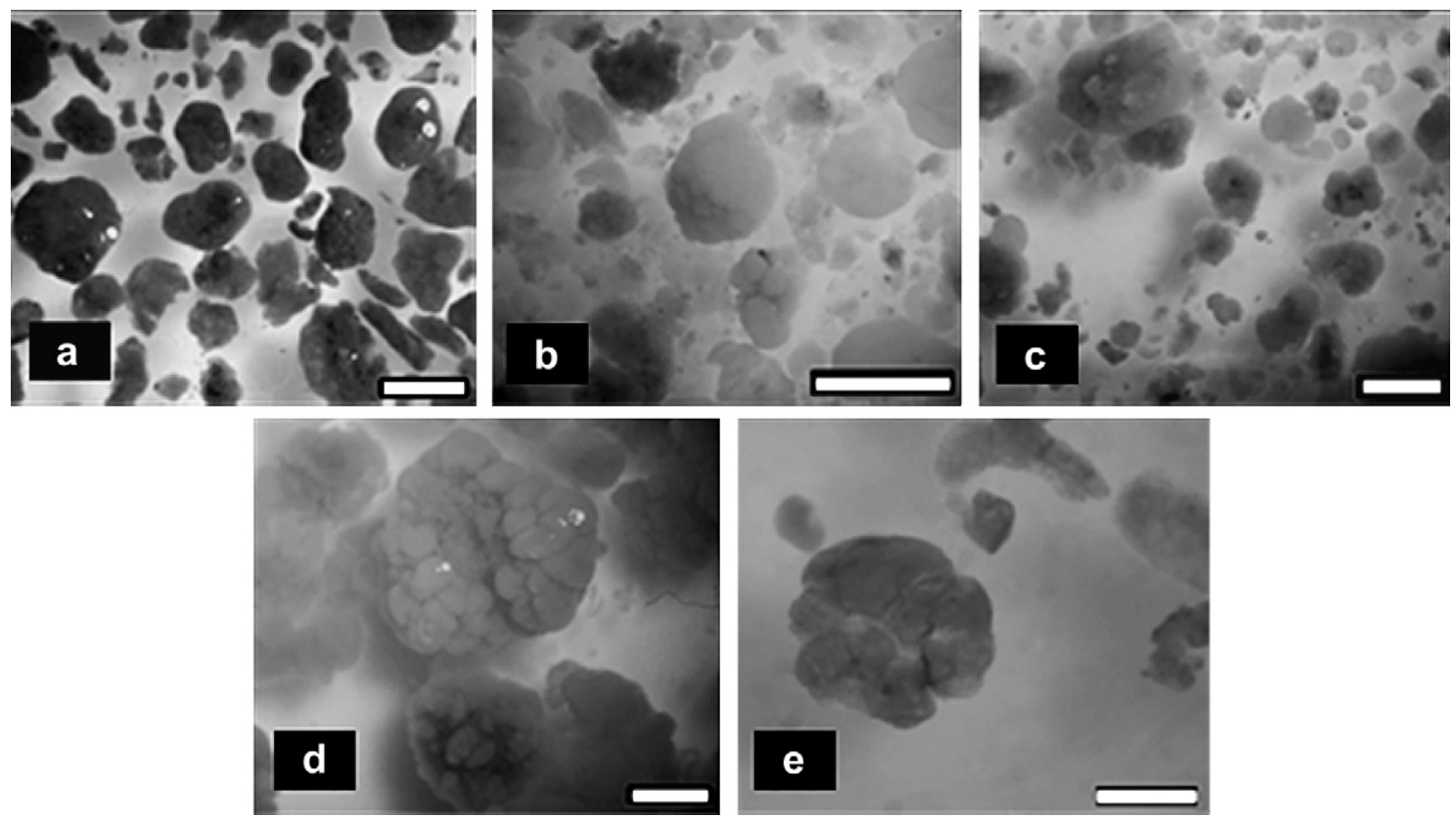

Fig. 2 - Morphology of the granules at the start-up of the SBR and during reactor operation. Granules used as inoculum for the start-up of the SBR (a); granules appearance after: 2 months operation (b); 3 months operation (c); 6 months operation (d) and 18 months operation (e). The size of the bar is $0.5 \mathrm{~mm}$.

\subsubsection{After bioaugmentation}

Bioaugmentation was performed using strain FP1 which is able to completely mineralize 2-FP with stoichiometric release of fluoride ion in suspension cultures supplied with $0.44 \mathrm{mM}$ of the compound (unpublished). This strain is able to degrade 2-FP up to concentrations of $4 \mathrm{mM}$. When the bioaugmentation was carried out, the SBR cycle time was changed to $12 \mathrm{~h}$ and the settling time was increased to $20 \mathrm{~min}$ (particles with a settling velocity larger than $0.9 \mathrm{~m} \mathrm{~h}^{-1}$ are retained in the reactor). The settling time was then gradually decreased back to 3 min (particles with a settling velocity larger than $6 \mathrm{~m} \mathrm{~h}^{-1}$ are retained in the reactor) during the first
3 months after augmentation. This strategy was chosen to prevent loss of Rhodococcus sp. strain FP1, as its settling velocity was much lower than that of the aerobic granular sludge present in the reactor, and also to promote its attachment to the granules. There are two main advantages in the attachment and integration of the strain into the granules, which are avoidance of wash out of the strain from the system, resultant from the retention of the microorganism within the granules, and providing higher protection from protozoan grazing (Nancharaiah et al., 2008).

In phase III the SBR was continuously fed with $0.22 \mathrm{mM}$ of 2-FP and $5.9 \mathrm{mM}$ of the co-substrate, acetate. The 2-FP

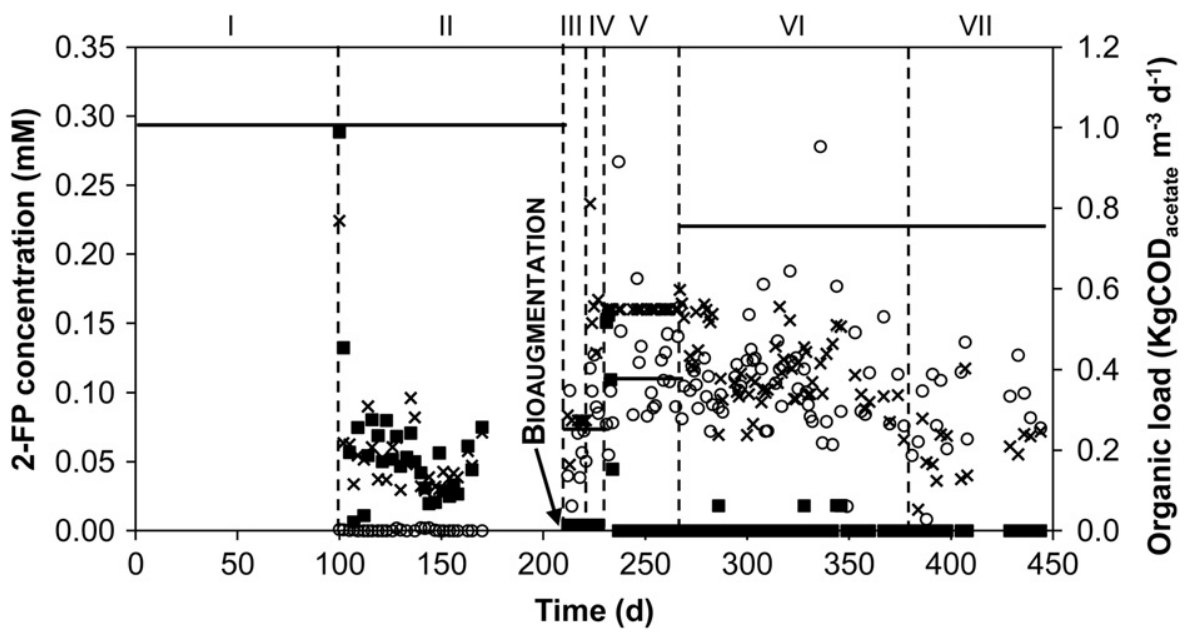

Fig. 3 - Biodegradation of 2-FP in the SBR before and after bioaugmentation with Rhodococcus sp. strain FP1. 2-FP inlet concentration measured after the 60 min feeding $(x)$, 2-FP outlet concentration $(\square)$, 2-FP degraded based on fluoride release $(\circ)$ and organic load based on acetate $\operatorname{COD}(-)$ are indicated. 
Table 2 - Summary of the performance of the SBR for 2-FP degradation.

\begin{tabular}{lccc} 
Phase & \multicolumn{3}{c}{ 2-FP mass balance (mmol) } \\
\cline { 2 - 4 } & 2-FP fed & 2-FP in the outlet & 2-FP degraded \\
\hline I & - & - & - \\
II & 4.13 & 4.27 & 0.028 \\
\multicolumn{4}{l}{ Bioaugmentation with } \\
III & 1.53 & 0.08 & \\
IV & 2.11 & 0.05 & 1.64 \\
V & 8.40 & 1.15 & 1.80 \\
VI & 17.90 & 0.18 & 6.54 \\
VII & 1.31 & 0 & 18.07 \\
Total from phase III to VII & & 2.14 \\
\multicolumn{4}{l}{ a 2-FP degraded based on fluoride release. } \\
\hline
\end{tabular}

concentration was then increased to $0.44 \mathrm{mM}$ in phases IV to VI. The results showed that 2-FP was completely degraded, suggesting that bioaugmentation was successfully achieved (Fig. 3, Table 2). During 2-FP degradation no intermediate metabolites, such as catechols and/or fluorocatechols, were detected in the samples. In some sampling days, such as in days 237 (phase V), 246 (phase V) and 336 (phase VI), the fluoride release obtained in the outlet of the SBR was higher than expected. This was most probably due to the adsorption of fluoride to the granules structure, which was then released to the effluent. The adsorption of fluoride to the aerobic granular sludge was studied in parallel with the SBR experiment and the results showed that granular sludge adsorb ca. $0.6 \mathrm{mmol} \mathrm{F}^{-} / \mathrm{L}_{\text {granules (data not shown). In some }}$ effluent samples, a small accumulation of 2-FP was observed (ca. $0.02 \mathrm{mM}$ of 2-FP). However, in the beginning of phase $\mathrm{V}$, 2-FP presence in the effluent of the SBR was more significant, which was most probably due to the decrease of the SBR cycle time from $12 \mathrm{~h}$ to $8 \mathrm{~h}$. This leads to a higher loading rate of 2-FP.

The 2-FP biodegradation profile observed in phase IV showed that this compound was degraded after $8 \mathrm{~h}$ and, based on this result, in phase $\mathrm{V}$ the SBR cycle time was reduced to $8 \mathrm{~h}$. Subsequently, it was observed that, during phase V, the 2FP was completely consumed within $4 \mathrm{~h}$ (Fig. $4 \mathrm{a}$ ), leading again to a change of the cycle time to $4 \mathrm{~h}$ (Fig. $4 \mathrm{~b}$ ). The main difference between phases VI and VII is the 2-FP concentration fed to the SBR (0.44 mM and $0.22 \mathrm{mM}$, respectively) (Table 1). The 2-FP conversion profile observed in phases VI and VII shows, respectively, that $0.44 \mathrm{mM}$ of $2-\mathrm{FP}$ are consumed within a $4 \mathrm{~h}$ period, with stoichiometric fluoride release after $4 \mathrm{~h}$, and that $0.22 \mathrm{mM}$ of 2-FP is consumed in just $2 \mathrm{~h}$, with stoichiometric fluoride release after $3 \mathrm{~h}$, suggesting that in phase VII the cycle time could have been further improved to a $3 \mathrm{~h}$ cycle.

The SBR bedvolume was measured along the different phases of bioreactor operation (Fig. 5). The results showed that immediately after bioaugmentation (phase III), the bedvolume of the SBR increased, suggesting that Rhodococcus sp. strain FP1 was attaching to the granules. From phase IV, a step decrease in the bedvolume was observed, being more significant between phases VI and VII. This was due to the total length of reactor operation, which was 444 days, after which
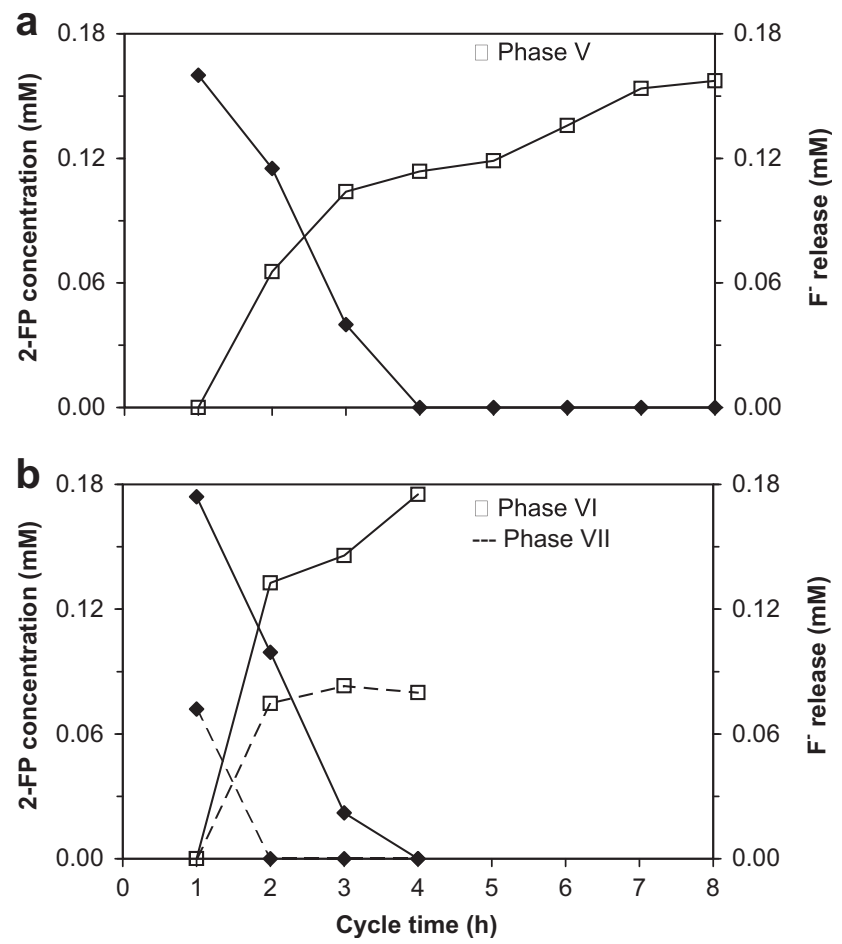

Fig. 4 - 2-FP biodegradation profiles during phase $V(a)$ and phases VI and VII (b). 2-FP concentration $(\diamond)$ and fluoride release $(\square)$ are indicated.

the granules became very small, like sand, but still very dense and with extraordinary settling properties (Fig. 2e).

\subsection{Analysis of the presence of Rhodococcus sp. strain FP1 in the SBR}

In order to follow the success of bioaugmentation, here defined as the capacity of the SBR to retain the degrading strain, aerobic granular sludge was crushed and plated in NA, close to the end of the experiment. After 3 days of incubation, different bacteria were isolated and the isolates were characterized through $16 \mathrm{~S}$ rRNA gene analysis. According to Blast

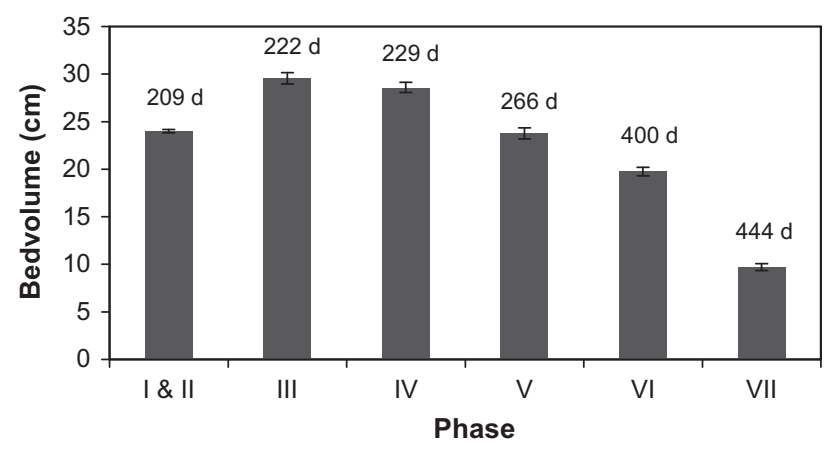

Fig. 5 - Profile of the bedvolume during SBR operation. The last day of reactor operation corresponding to each phase is indicated at the top of the bars. Values are means \pm standard error of the mean (SEM). 
results Rhodococcus sp. strain FP1 was recovered from the reactor. This strongly indicates the success of the bioaugmentation, suggesting that granular sludge is capable to incorporate and retain specialized degraders. Furthermore, this indicates that strain FP1 probably had a key role on 2-FP degradation. Previous studies have shown unsuccessful flocs bioaugmentation with labeled strains, indicating grazing by protozoa and cell wash out as the main reasons (Eberl et al., 1997; Van Veen et al., 1997), which did not happen in our study. Containment of bioaugmented strains within GAC biofilm reactors has been proven successful (Carvalho et al., 2006b; Emanuelsson et al., 2008), but in granule technology there is no physical immobilization material and, thus, we could speculate that containment of the degrading strains would have been more difficult. This further corroborates the robustness of the granular technology for application in the treatment of wastewaters.

\section{Conclusions}

This study showed that it is possible to biologically remove toxic compounds, like 2-FP used in this study, from wastewaters using granular sludge SBRs. The main conclusions drawn from this work are:

- The aerobic granular sludge used to inoculate the SBR was not able to degrade the 2-FP fed to the reactor;

- Bioaugmentation with strain FP1 was successfully achieved, as complete biodegradation of 2-FP was reached;

- Strain FP1 was successfully recovered from the aerobic granules after 444 days of SBR operation, suggesting that granular sludge can integrate specialized degraders;

- Granular SBRs are very promising for the treatment of wastewaters containing toxic compounds as granulation may help retaining inoculated specialized degrading strains;

- This study clearly reinforces the need for bioaugmentation in cases where biodegradation of highly recalcitrant compounds is targeted.

\section{Acknowledgments}

Anouk F. Duque and Maria F. Carvalho thank the research grants from Fundação para a Ciência e Tecnologia (FCT), Portugal (Ref. SFRH/BD/30771/2006 and SFRH/BPD/44670/2008, respectively) and Fundo Social Europeu (FSE) (Programa Operacional Potencial Humano (POPH), Quadro de Referência Estratégico Nacional (QREN)). This work was supported by the FCT Project - PTDC/BIO/67306/2006.

\section{REFERENCES}

Altschul, S.F., Madden, T.L., Schaffer, A.A., Zhang, J., Zhang, Z., Miller, W., Lipman, D.J., 1997. Gapped BLAST and PSI-BLAST: a new generation of protein database search programs. Nucleic Acids Research 25, 3389-3402.
APHA, 1998. Standard Methods: For the Examination of Water and Wastewater, twentieth ed. American Public Health Association/American Water Works Association/Water Environment Federation, Washington, DC, USA.

Beun, J.J., Hendriks, A., van Loosdrecht, M.C.M., Morgenroth, E., Wilderer, P.A., Heijnen, J.J., 1999. Aerobic granulation in a sequencing batch reactor. Water Research 33 (10), 2283-2290.

Beun, J.J., van Loosdrecht, M.C.M., Heijnen, J.J., 2000. Aerobic granulation. Water Science and Technology 41 (4-5), 41-48.

Beun, J.J., van Loosdrecht, M.C.M., Heijnen, J.J., 2002. Aerobic granulation in a sequencing batch airlift reactor. Water Research 36 (3), 702-712.

Buitron, G., Schoeb, M.-E., Moreno-Andrade, I., Moreno, J., 2005. Evaluation of two control strategies for a sequence batch reactor degrading high concentration peaks of 4chlorophenol. Water Research 39, 1015-1024.

Caldeira, M., Heald, S.C., Carvalho, M.F., Vasconcelos, I., Bull, A.T., Castro, P.M.L., 1999. 4-Chlorophenol degradation by a bacterial consortium: development of a granular activated carbon biofilm reactor. Applied Microbiology and Biotechnology 52, 722-729.

Carucci, A., Milia, S., De Gioannis, G., Piredda, M., 2008. Acetate-fed aerobic granular sludge for the biodegradation of chlorinated phenols. Water Science and Technology 58 (2), 309-315.

Carucci, A., Milia, S., De Gioannis, G., Piredda, M., 2009. Acetatefed aerobic granular sludge for the degradation of 4chlorophenol. Journal of Hazardous Materials 166, 483-490.

Carucci, A., Milia, S., Cappai, G., Muntoni, A., 2010. A direct comparison amongst different technologies (aerobic granular sludge, SBR and MBR) for the treatment of wastewater contaminated by 4-chlorophenol. Journal of Hazardous Materials 177, 1119-1125.

Carvalho, M.F., Ferreira, M.I.M., Moreira, I.S., Castro, P.M.L., Janssen, D.B., 2006a. Degradation of fluorobenzene by Rhizobiales strain F11 via ortho cleavage of 4-fluorocatechol and catechol. Applied Environmental Microbiology 72, 7413-7417.

Carvalho, M.F., Ferreira Jorge, R., Pacheco, C.C., De Marco, P., Henriques, I.S., Correia, A., Castro, P.M.L., 2006b. Long-term performance and microbial dynamics of an up-flow fixed bed reactor established for the biodegradation of fluorobenzene. Applied Microbiology and Biotechnology 71, 555-562.

De Bruin, L.M.M., de Kreuk, M.K., van der Roest, H.F.R., Uijterlinde, C., van Loosdrecht, M.C.M., 2004. Aerobic granular sludge technology: an alternative to activated sludge? Water Science and Technology 49 (11-12), 1-7.

De Kreuk, M.K., Heijnen, J.J., van Loosdrecht, M.C.M., 2005. Simultaneous COD, nitrogen, and phosphate removal by aerobic granular sludge. Biotechnology and Bioengineering 90 (6), 761-769.

Eberl, L., Schulz, R., Ammendola, A., Geisenberger, O., Erhart, R., Sternberg, C., Molin, S., Amann, R., 1997. Use of green fluorescent protein as a marker for ecological studies of activated sludge communities. FEMS Microbiology Letters 149, 77-83.

Emanuelsson, M.A.E., Osuna, M.B., Sipma, J., Castro, P.M.L., 2008. Treatment of halogenated organic compounds and monitoring of microbial dynamics in up-flow fixed bed reactors under sequentially alternating pollutant scenarios. Biotechnology and Bioengineering 99, 800-810.

Fava, F., Armenante, P., Kafkewitz, D., 1995. Aerobic degradation and dechlorination of 2-chlorophenol, 3-chlorophenol and 4chlorophenol by a Pseudomonas pickettii strain. Letters in Applied Microbiology 21, 307-312.

Haggblom, M.M., 1992. Microbial breakdown of halogenated aromatic pesticides and related compounds. Microbiology Reviews 103, 29-72.

Jiang, H.L., Tay, J.H., Tay, S.T.L., 2002. Aggregation of immobilized activated sludge cells into aerobically grown microbial granules for the aerobic biodegradation of phenol. Letters in Applied Microbiology 35, 439-445. 
Key, B., Howell, R., Criddle, C., 1997. Fluorinated organics in the biosphere. Environmental Science and Technology 31, 2445-2454.

Lane, D.J., 1991. 16S/23S rRNA sequencing. In: Stackebrandt, E., Goodfellow, M. (Eds.), Nucleic Acid Techniques in Bacterial Systematics. John Wiley and Sons Ltd, West Sussex, England.

Morgenroth, E., Sherden, T., van Loosdrecht, M.C.M., Heijnen, J.J., Wilderer, P.A., 1997. Aerobic granular sludge in a sequencing batch reactor. Water Research 31 (12), 3191-3194.

Murphy, C.D., Clark, B.R., Amadio, J., 2009. Metabolism of fluoroorganic compounds in microorganisms: impacts for the environment and the production of fine chemicals. Applied Microbiology and Biotechnology 84, 617-629.

Nancharaiah, Y.V., Joshi, H.M., Hausner, M., Venugopalan, V.P., 2008. Bioaugmentation of aerobic microbial granules with Pseudomonas putida carrying TOL plasmid. Chemosphere 71, 30-35.

Osuna, M.B., Sipma, J., Emanuelsson, M.A.E., Carvalho, M.F., Castro, P.M.L., 2008. Biodegradation of 2-fluorobenzoate and dichloromethane under simultaneous and sequential alternating pollutant feeding. Water Research 42, 3857-3869.

Quan, X., Shi, H., Wang, J., Qian, Y., 2003. Biodegradation of 2,4dichlorophenol in sequencing batch reactors augmented with immobilized mixed culture. Chemosphere 50, 1069-1074.

Rainey, F.A., Ward-Rainey, N., Kroppenstedt, R.M., Stackebrandt, E., 1996. The genus Nocardiopsis represents a phylogenetically coherent taxon and a distinct actinomycete lineage: proposal of Nocardiopsaceae fam. nov. International Journal of Systematics Bacteriology 46, 1088-1092.

Rittmann, B.E., Whiteman, R., 1994. Bioaugmentation: a coming age. Water Quality International 1, 12-16.

Tay, S.T.L., Moy, B.Y.P., Jiang, H.L., Tay, J.H., 2005a. Rapid cultivation of stable phenol degrading granules using acetate fed granules as microbial seed. Journal of Biotechnology 115, 387-395.

Tay, S.T.L., Moy, B.Y.-P., Maszenan, A.M., Tay, J.-H., 2005b. Comparing activated sludge and aerobic granules as microbial inocula for phenol biodegradation. Applied Microbiology and Biotechnology 67, 708-713.

Van Veen, J.A., van Overbeek, L.S., van Elsas, J.D., 1997. Fate and activity of microorganisms introduced into soil. Microbiology and Molecular Biology Reviews 61, 121-135.

Wang, S.G., Liu, X.W., Zhang, H.Y., Gong, W.X., Sun, X.F., Gao, B.Y., 2007. Aerobic granulation for 2,4-dichlorophenol biodegradation in a sequencing batch reactor. Chemosphere 69, 769-775.

Xu, H., Tay, J.H., Foo, S.K., Yang, S.F., Liu, Y., 2004. Removal of dissolved copper(II) and zinc(II) by aerobic granular sludge. Water Science and Technology 50, 155-160.

Yu, Z., Mohn, W.W., 2001. Bioaugmentation with resin-aciddegrading bacteria enhances resin acid removal in sequencing batch reactors treating pulp mill effluents. Water Research 35 (4), 883-890. 